\title{
A Study on Literary Translation from the Perspective of Feminism
}

\author{
Zhihai Chen, Zhengpei Chen
}

Changchun Institute of Technology, Changchun, Jilin, 130012

\begin{abstract}
Keywords: Feminism; Feminism Translation Theory; Hijacking; Literary Translation.
\end{abstract}
\begin{abstract}
The strategy of hijacking is the most controversial strategy of the three translation strategies which feminist translators use commonly. Feminist translators manipulate the text with feminist preference to those viewpoints which have no relation with feminism. The research of the strategy of literary translation from the perspective of feminism has certain reference value for some related topics from now on. And this research also provides readers reference for selecting Chinese versions of feminist foreign works.
\end{abstract}

\section{An Overview of Feminism and Literary Translation}

Feminism refers to the social theory and political movement that is created and launched to end sexism, sexual exploitation, sexual discrimination and sexual oppression and to promote sexual equality. In addition to the criticism, it also focuses on the analysis of gender inequality as well as the promotion of the rights, interests and issues of gender which lies in a low position at that time. The theory of Feminism is a complicated object, and can be summed up in one sentence: to achieve gender equality in all mankind ( $\mathrm{Li}, 2005: 1)$.

\subsection{A brief introduction to Feminism}

Feminist movement in western countries has a long history and can be broadly divided into three eras: the first generation of Feminism from the second half of the 19th century to the beginning of the 20th century, Modern Feminism from the beginning of the 20th century to the 1960s and Postmodern Feminism from the 1960s up to now.

Liberal Feminism is the early manifestation of Feminism (Wang, 2006: 46). It was originated in the Enlightenment in the 18th century and French Revolution, standing for equality between men and women, and its initial claim was that women enjoyed the same rights as men in all aspects. Under the impetus of emerging bourgeoisie forces represented by enlightenment thinkers, women were actively involved in the struggle from beginning to end during the period of French Revolution. However, they increasingly felt in the process that the "human" in the "natural human rights" advocated by the Enlightenment dose not include women and "equality" is just a beautiful lie. And then they began to fight against the bourgeois patriarchal society. In 1791, Mary Wollstonecraft wrote the book Vindication of the Rights of Women to strongly urge that women should have the same three independent rights as men, which are the right to work, the right to education and the right to participate in politics. Taking Watt's improved steam engine as a mark, human society has entered the "steam era", which is the first industrial revolution period. The improvement of the steam engine has promoted the popularization of the machine and the establishment of the large factory system, which lead to tens of thousands of working women working in the factory. Accordingly women were gathering strength.

From the beginning of the 20th century to the 1960s, humankind has suffered the ravages of two world wars, which caused the turbulent global society. And the society was forced to build a new order. In this period Feminism split into three streams which were "Radicalism Feminism" represented by Kate Millett and Catharine MacKinnon, "Marxism/Socialist Feminism" represented by Juliet Michael and "Liberal Feminism" represented by Betty Friedan. Marxism/Socialist Feminism required the equality of men and women and the status of women in the material mainly from the aspect of economy and class struggle. But Radicalism Feminism and Liberal Feminism pursued women's liberation in the aspect of "sex". 
With the western society stepping into the post industrial era, Postmodern Feminism began to replace the traditional feminism which are Liberal Feminism, Radicalism Feminism, and Socialist Feminism and so on. In this period, the feminist movement gradually silenced but the development of feminism in theory was a potential sparks of fire. Under the banner of feminism, there were many factions. They had many internal contradictions and conflicts but sometimes they could hold together to fight against the external enemies and take aim at male authority. In a word, the skeptical spirit and the anti-cultural attitude in Postmodern Context have brought vigor and vitality to Feminism by resolute attitude to tradition, strategy to value digestion and high-spirited spirit of rebellion and Deconstruction (Wang, 2006: 49).

The development of Feminism has changed the traditional way of thinking and facilitated the awakening of women's self consciousness; in the meanwhile, it has also propelled the development of Women's Liberation Movement and improved the status of women in politics, economy, and culture and so on.

\subsection{The influence of Feminism on literary translation}

Feminism refutes traditional hierarchy and traditional position of female and questions the fidelity rule and the central meaning brings new development and promotion to translation studies (Lan, 2005: 102). The influence of Feminism on literary translation can be seen from the following three aspects.

First is the influence of Feminism on the meaning of text. One of the striking features of Feminism is its subversive trait, negating absolute authority, which reflecting in literary translation is to disprove the supreme status of the original text. For Feminism, each text has its author's identity, as well as the features of ideology and cultural and political environment left behind in the author's time; and every reader will add his or her unique sentiment to the meaning of the text. Consequently, the meaning of a text is diversified, causing each reader's different understanding of the text. Thus the authority of the original text in studies of traditional translation needs to take into consideration here. Literary translation in the understanding of feminism theory is the process of re-creation of the text.

Secondly, Feminism affects people's perspective and employ of language. Feminism holds that language is not only a tool of communication, but also a tool of control. In the view of feminists, the language used by people is the language governed by patriarchy, which is one of the major origins of the oppression of females. Through language, women were inculcated the values that men are superior to women, submitting their subordinate status. The standpoint of Feminism on language is bound to have an impact on literary translation, and a typical example is to translate body language in feminism works.

And the last is the influence of Feminism on the status of the translators. For a long time, translations were considered to be derived from the original and translators were often placed in the passive position like a "servant" as well. Compared with men, women were in the same subordinate and derived status as translations. Feminism radicals commenced from liberating language and they even regarded language as the fundamental cause of the discrimination to women. The reformists also considered that at least language presented the social society of the discrimination against women. In practice, Feminism strongly advocated an interventionist translation practice for a feminist creation on the text. It can be illustrated from the translation theory and translation practice of Feminism that the author is no longer the sole authority to dominate the meaning of the text and the translator is no longer an appendage of the author, and the status and identity of women and translators have been improved and demonstrated unprecedentedly.

\section{Theoretic Study of Feminism Translation}

Feminism translation theory originated from the western feminism movement and its intention is to eliminate discrimination against women in translation study and practice, redefine the relationship between the translation and the original and point out that translation should not only refer to specific language skills, but also include culture, ideology and other issues. To achieve these intentions, feminist translators usually adopt three translation strategies, which are preface and footnotes, supplementing and hijacking. 


\subsection{The concept of Feminism Translation}

Feminist movement impacts on the society in many aspects. It ensures the citizenship of women, improves the employment rate of women, enhances the western women's autonomy of the family name after their marriages and even leaves a significant imprint on translation. Feminism Translation aims to achieve equality between men and women in all mankind and negates the patriarchal gender order under the rule of men. From the perspective of feminism, it highlights the image of women in translation to make people know more about women. The essence of feminist translation theory is to achieve the purpose of improving the social status and political status of women by emphasizing the political nature of language (Wu, 2010: 515).

Feminism provides a new research perspective for translation studies, which re-interprets some important concepts in traditional translation theories, and puts forward some unique perspectives. First, feminism translation theory subverts the "faithfulness" principle of traditional translation theory and stresses the "creative betrayal". Traditional translation theory regards "fidelity" or "faithfulness" as the core of translation standard and considers that the translation must be faithful to the original text. Feminist translators firmly argue against this viewpoint for "faithfulness" usually means the deprivation of the discourse power of women. The feminists claim that translation provides an opportunity for both women and translators to resist their unfavorable position in their respective hierarchical order (Zhang, 2005: 436). The creation of each text is a consequence of the author's subjectivity, the cultural context and the ideology of the text and other factors. Consequently, it is necessary for a feminist translator to bring herself into the text, imitate those methods of writing advocated by feminist writers and manipulate the original with feminist preference to reverse the submission and silence in the past in female translation activities. Secondly, it redefines the relationship between the original and the translation and underlines the translator's subjectivity. Traditional translation theory regards the original and the translation as a binary opposition and holds that the original is dominant and the translation is uncreative, subordinate and derived. But feminist translators consider that both the original and the translation are the crystallization of human wisdom. The translation extends the life of the original and opens up a broader living space for the original. The two should enjoy the equal status. Finally, feminist translators eliminate gender discrimination in language translation through a large number of translation practices. Shouldering the double historical tasks of the vindication for translation and female, western feminist translation theorists wage effective struggles and advocate intervention strategies in translation. Flotow puts forward three translation strategies and they are preface and footnotes, supplementing and hijacking, which are commonly used by the feminist translators to interfere the text. The strategy of preface and footnotes refers to the description of the translation process which aims to stress the difference of feminist translators in translation. The strategy of supplementing is the creative activity to balance the differences between two languages. And the strategy of hijacking refers to the manipulation of feminist translators with feminist preference to those viewpoints which have no relation with feminism.

The emergence and development of feminism translation theory injects fresh blood for translation studies and triggers people's contemplation towards traditional translation as well. Feminism translation theory, standing on the shoulders of the traditional structuralism translation theory, provides people new theoretical foundation to reflect on translation standards, translation strategies, translator's subjectivity and other issues. And it makes people pay more attention to the value orientation of translation and have a deep understanding of the significance of translation activities.

\subsection{Strategies of Feminism Translation}

The redefinition of the relationship between the translation and the original deconstructs the rule of being faithful to the original text. For feminist translation, fidelity is to be directed toward neither the author nor the reader, but toward the writing project--a project in which both writer and translator participate (Simon, 1996: 2). Flotow enumerate three translation strategies in common use by feminist translators and they are preface and footnotes, supplementing and hijacking. 


\subsubsection{Preface and footnotes}

Preface and footnotes is a kind of translation strategy for translators to express the author's intention and introduce what translation strategies they will use. Besides, feminist translators think it as an effective way to express their own feelings. They usually exploit preface to explain the main purpose of the text, illustrate their purpose of material selection and translation, summarize their translation strategies and state their views. When feminist translators think the expressions in the original can be used to achieve their political purpose, they employ footnotes to explain and illustrate their female ideology from the perspective of Feminism in order not to destruct the fluency and format of source language.

Zhang Ailing wrote and translated a great deal of works but only wrote prefaces for her three translations, which are The Old Man and the Sea, The Selected Works of Emerson and the Sing-song Girls of Shanghai. In the translation of The Old Man and the Sea, Zhang mentioned in the preface her love for this work and her worries about the translation effect and readers' responses. Furthermore, she also explained that her translation was not only for men since no matter men or women could have the old man's perseverance in the book. Through this book, Zhang wanted to encourage both men and women to steel themselves. These all embody her expectation to establish a society of equality between men and women.

\subsubsection{Supplementing}

Supplementing is a kind of intervention to make up the difference between two languages and is also defined as a translation skill which can make up for the disappearance of the features of the original text in the process of translation. But feminist translators pay attention to the way to supplement the expression of sex distinction of the original. They deal with word games to add their own perspectives. The strategy of supplementing is also used in Zhang's Chinese version of The Legend of the Sleepy Hollow, for example,

The original: Some of the damsels mounted on pillion behind their favorite swains, and their light-hearted laughter, mingling with the clatter of hoofs, echoed along the silent woodlands, sounding fainter and fainter until they gradually died away. (Irving, 1967: 37)

The translation: 有些姑娘们高坐在女鞍上，在她们最中意的情郎背后，她们轻快的笑声与 蹄声得得混合在一起, 在那沉寂的树林中引起了回声, 那声音越来越轻, 终于渐渐归于死 寂。(Zhang, 1967: 37)

In the translation of this sentence, Zhang uses the strategy of supplementing to the word "pillion", which has nothing to do with gender. But she adds something about gender into "pillion" to say more about the tradition. For a feminist translator, it is quite important to commentate the difference in riding between men and women in western countries in the past. At that time, women were confined to the side-saddle which was uncomfortable for them in such posture when riding. Therefore, the reason why Zhang uses “女鞍” instead of “马鞍” to translate the word “pillion” is very easy to understand: to emphasize the special usage of pillion for women and the difference between men and women which results in women's suffering. By using supplementing, the unfair treatment to women attracts the readers' attentions.

\subsubsection{Hijacking}

Hijacking, which is the most controversial strategy of all feminist translation strategies, refers to the manipulation of feminist translators with feminist preference to those viewpoints which have no relation with feminism. Feminist translators give themselves the right to manipulate the incorrect text in politics and they use hijacking to change the meaning of words or sentences to stress feminism and their female consciousness. The strategy of hijacking is also reflected in Zhang's translation of The Legend of the Sleepy Hollow, for example,

The original: Could that girl have been playing off any of her coquettish tricks? (Irving, 1967: 38)

The translation: 那女孩子是不是在那里玩手段，捉弄人? (Zhang, 1967: 38)

In the original sentence, “coquettish” means of or like a girl or woman who flirts, which shows the author's discrimination to women. Thus, Zhang uses the strategy of hijacking to avoid the original 
meaning of debasing women. It can be seen that the use of hijacking here is not to distort the original maliciously, but to erase the author's malicious damage to women.

The strategy of hijacking is one of the three translation strategies commonly used by feminist translators and also plays an important role in feminist translation theory. Feminist translation emphasizes translators' subjectivity and interference to the original, which subverts the standard of "faithfulness" completely in traditional translation. To achieve this purpose, feminist translators make use of the strategy of hijacking, which shows the importance of this strategy.

\section{Conclusion}

In summary, when translating the literary works with feminist preference to Chinese, the translators' feminist consciousness will have an obvious impact on the style of their translations and will help translators understand and interpret feminist literary works better and embody the author's writing intention in their translation. However, to achieve their purpose in politics, feminist translators overemphasize the manipulation of language and the interference of the original and overuse the strategy of hijacking. In a way, they distort the essence of translation which causes excessive narrated consciousness of subject.

\section{References}

[1] Dreiser, T. Sister Carrie [Z]. Beijing: Foreign Language Teaching and Research Press, 1992.

[2] Irving, W. The Legend of the Sleepy Hollow [Z]. Hong Kong: World Today Press, 1967.

[3] Simon, Sherry. Gender in Translation [M]. London and New York: Routledge, 1996.

[4] Von Flotow, Luise. Translation and Gender: Translating in the "Era of Feminism" [M]. Manchester: St. Jerome Publishing, 1997. 